\title{
Cryptococcal Pleural Effusion in a Patient with Chronic Renal Failure Receiving Long-term Corticosteroid Therapy for Rheumatoid Arthritis
}

\author{
Masahiko FukuchI, Yutaka Mizushima, Tooru Hori and Masashi Kobayashi
}

\begin{abstract}
A 52-year-old woman with a seven-year history of rheumatoid arthritis (RA) was transferred to our department with chronic renal failure to undergo hemodialysis. She had been treated with prednisolone for a long time, and had renal amyloidosis secondary to RA. During her hospitalization, a left pleural effusion developed. Pleural fluid cultured positive for Cryptococcus neoformans $(\mathrm{CN})$, and the $\mathrm{CN}$ antigen was detected in both pleural fluid and serum. Chest computerized tomography revealed an infiltrate shadow in the left lower lung field suggestive of $\mathrm{CN}$ infection. This was successfully treated with anti-fungal agents. Pleural effusion is an unusual manifestation of pulmonary cryptococcosis. We should consider a diagnosis of $\mathrm{CN}$ infection when pleural effusion is observed in compromised patients such as those receiving a long-term corticosteroid treatment. (Internal Medicine 37: 534-537, 1998)
\end{abstract}

Key words: Cryptococcus neoformans $(\mathrm{CN})$, compromised host, secondary amyloidosis, antigen test

\section{Introduction}

Cryptococcal pulmonary infection rarely occurs in healthy or compromised persons (1-10). Cryptococcus neoformans $(\mathrm{CN})$ infection associated with pleural effusion is uncommon, even in patients with acquired immunodeficiency syndrome (AIDS) (4, 6-10). Here, we report a rare case of pleural effusion due to $\mathrm{CN}$ that developed in a patient with chronic renal failure receiving long-term corticosteroid treatment for rheumatoid arthritis (RA).

\section{Case Report}

A 52-year-old woman was transferred to our department on December 3, 1996 to receive hemodialysis treatment for chronic renal failure. She had been treated with prednisolone (PSL) (maintenance dose of $10 \mathrm{mg} /$ day) for rheumatoid arthritis (RA) since she was 45 years old. At 50 years of age, she had undergone a left nephrectomy due to renal cell carcinoma, and was diagnosed with renal amyloidosis. Since then, non-steroidal anti-inflammatory drugs (NSAID) had been avoided to guard the renal function. Her RA state had been stable and was stage III and class 2 according to Steinbrocker's classification (11). On admission, her serum creatinine (Cr) level was $4.4 \mathrm{mg} / \mathrm{dl}$, and she had gained $10 \mathrm{~kg}$ in weight. Chest roentgenograms revealed pulmonary congestion and bilateral pleural effusion. She underwent hemodialysis twice weekly from December 5, and thereafter the bilateral pleural effusion resolved and her general condition improved. However, ileus occurred in midJanuary 1997, and a loop colostomy was carried out on January 23 in the Department of Surgery. Later, her ileus proved to be paralytic due to intestinal amyloidosis. After surgery, disseminated intravascular coagulation (DIC) occurred which was triggered by postoperative infection, and she was transferred back to our ward on January 29.

On the same day (1/29), laboratory data (Table 1$)$ showed thrombocytopenia $\left(3.5 \times 10^{4} / \mu \mathrm{l}\right)$, enhanced coagulation activity, and raised C-reactive protein (CRP) $(15.7 \mathrm{mg} / \mathrm{dl})$. Following treatment with antibiotics and gabexate mesilate (FOY), her platelet counts and CRP returned to normal levels, $40.2 \times 10^{4} / \mu \mathrm{l}$ and $0.3 \mathrm{mg} / \mathrm{dl}$, respectively (2/10). However, her fever returned on February 11 and her CRP was elevated to $9.9 \mathrm{mg} / \mathrm{dl}$ on the Feb. 17. Chest roentogenograms (2/17) (Fig. 1) revealed a left pleural effusion. The next day, thoracentesis was carried out and Cryptococcus neoformans was cultured (Table 2). The $\mathrm{CN}$ antigen was also detected in both pleural fluid and serum. No signs of meningitis were observed. Chest computerized tomography (CT) (Fig. 2) revealed an infiltrate shadow in the left

From the First Department of Internal Medicine, Toyama Medical and Pharmaceutical University, Toyama

Received for publication August 15, 1997; Accepted for publication March 24, 1998

Reprint requests should be addressed to Dr. Yutaka Mizushima, the Department of Geriatrics, Hirosaki University, School of Medicine, Hirosaki 036-8126 
Pleural Effusion due to $C$. neoformans

Table 1. Laboratory Data on Day of Transfer from the Surgical Department (1/29)

\begin{tabular}{|c|c|c|c|}
\hline White blood cells & $8,620 / \mu \mathrm{l}(8,600)^{*}$ & anti-HIV antibody & $(-)$ \\
\hline neutrophils & $77.4 \%$ & HBs antigen & $(-)$ \\
\hline lymphocytes & $15.0 \%$ & anti-HCV antibody & $(-)$ \\
\hline monocytes & $6.3 \%$ & & \\
\hline eosinophils & $0.9 \%$ & Prothrombin time & $77.9 \%$ \\
\hline basophils & $0.3 \%$ & Fibrinogen & $498 \mathrm{mg} / \mathrm{dl}$ \\
\hline Red blood cells & $204 \times 10^{6} / \mu 1(298)$ & FDP & $6.9 \mu \mathrm{g} / \mathrm{ml}$ \\
\hline Hemoglobin & $6.1 \mathrm{~g} / \mathrm{dl}(8.6)$ & AT-3 activity & $51.2 \%$ \\
\hline Platelet & $3.5 \times 10^{4} / \mu 1(3.0)$ & D-dimer & $3.1 \mu \mathrm{g} / \mathrm{ml}$ \\
\hline ESR & $75 \mathrm{~mm} / \mathrm{h}$ & Urinalysis & \\
\hline C-reactive protein & $15.7 \mathrm{mg} / \mathrm{dl}$ & protein & $(+++)$ \\
\hline \multirow[t]{2}{*}{ RAHA } & $\times 640$ & sugar & $(++)$ \\
\hline & & occult blood & $(+)$ \\
\hline Total protein & $4.7 \mathrm{~g} / \mathrm{dl}$ & cast & $(+)$ \\
\hline Albumin & $53.0 \%$ & bacteria & $(-)$ \\
\hline$\alpha_{1}$-globulin & $4.5 \%$ & & \\
\hline$\alpha_{2}$-globulin & $12.2 \%$ & Blood culture: bacteria & $(-)$ \\
\hline$\beta$-globulin & $8.5 \%$ & & \\
\hline$\gamma$-globulin & $21.8 \%$ & Arterial blood gas (room air) & \\
\hline Aspartate aminotransferase & $8 \mathrm{IU} / l$ & $\mathrm{PH}$ & 7.386 \\
\hline Alanine aminotransferase & $1 \mathrm{IU} / l$ & $\mathrm{PaO}_{2}$ & 66.8 torr \\
\hline Lactate dehydrogenase & $263 \mathrm{IU} / l$ & $\mathrm{PaCO}_{2}$ & 28.2 torr \\
\hline $\mathrm{Na}$ & $141 \mathrm{mEq} / \mathrm{l}(139)$ & $\mathrm{HCO}_{3}$ & $16.9 \mathrm{mEq} / \mathrm{l}$ \\
\hline $\mathrm{K}$ & $5.0 \mathrm{mEq} / l(4.3)$ & & \\
\hline $\mathrm{Cl}$ & $111 \mathrm{mEq} / \mathrm{l}(106)$ & PPD skin test: & negative \\
\hline Blood urea nitrogen & $39 \mathrm{mg} / \mathrm{dl}(20)$ & & \\
\hline Creatinine & $3.8 \mathrm{mg} / \mathrm{dl}(1.4)$ & & \\
\hline
\end{tabular}

* Parentheses indicate data following hemodialysis. Body weight was reduced by $1.5 \mathrm{~kg}$ following hemodialysis. ESR: erythrocyte sedimentation rate, FDP: fibrinogen degradation product, HIV: human immunodeficiency virus, AT-3: antithrombin 3, HCV: hepatitis C virus, PPD: purified protein derivative of tuberculin, RAHA: rheumatoid factor.

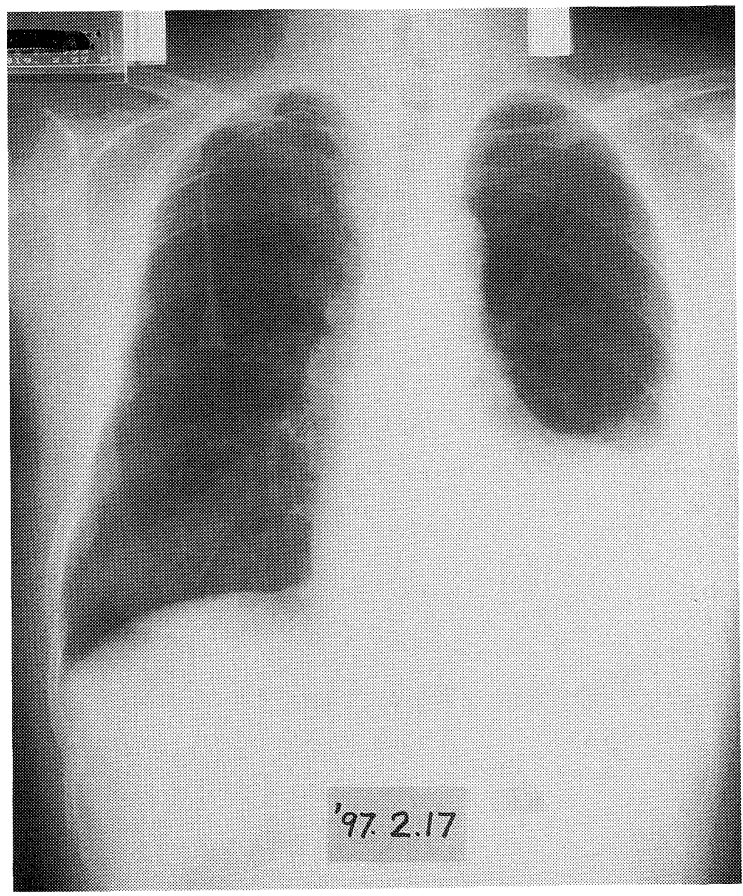

Table 2. Characteristics of Pleural Effusion (2/18)

Color: yellow, turbid

Lymphocyte-predominant $\quad 4,320 / \mu \mathrm{l}$

Specific gravity $\quad 1.020$

Total protein $2.5(4.9)^{*} \mathrm{~g} / \mathrm{dl}$

Albumin $1.4(2.3) \mathrm{g} / \mathrm{dl}$

Lactate dehydrogenase 364 (248) IU/l

Glucose $\quad 110 \mathrm{mg} / \mathrm{dl}$

Adenosine deaminase $27.8 \mathrm{IU} / l$

Culture: Cryptococcus neoformans (+) M. tuberculosis (-)

Cytology: class II

*Parentheses indicate serum levels on the same day. Hemodialysis was not performed on this day.

Figure 1. Chest roentgenograms on readmission (2/ 17) revealed a left pleural effusion. 
lower lung field suggestive of $\mathrm{CN}$ infection. No mediastinal or hilar lymphadenopathy was observed. The serum level of adenosine deaminase (ADA) was not high enough to strongly suspect the M. tuberculosis infection. Pleural effusion due to RA also appeared to be unlikely, because the activity of RA was stable clinically and the level of glucose in the effusion was not low $(110 \mathrm{mg} / \mathrm{dl})$. Anti-fungal therapy was begun on Feb. 21 (Fig. 3). She was first treated with amphotericin B (AMPH)

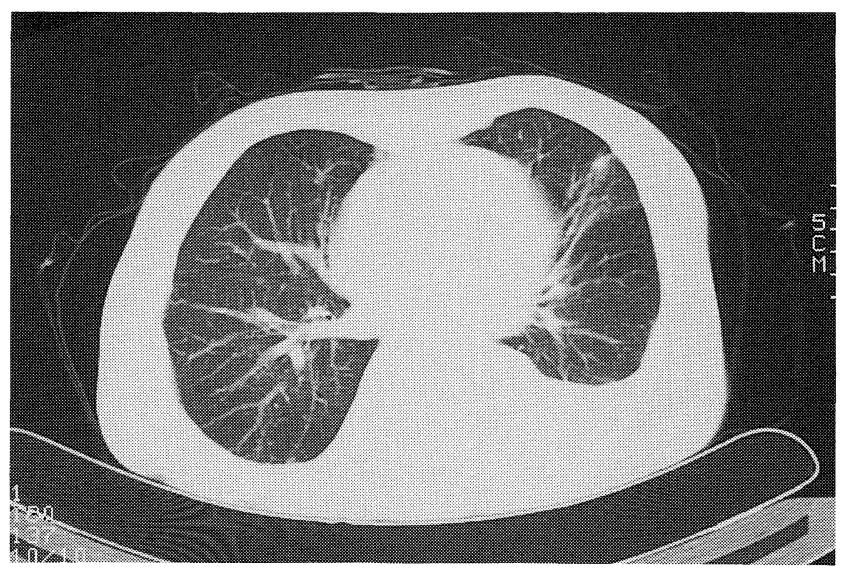

Figure 2. Chest CT scan (3/7) revealed a parenchymal infiltrate shadow in the left lower lung field suggestive of $\mathrm{CN}$ infection and a left pleural effusion. intravenously (div), and then intrapleurally (ipl). Culture of pleural fluid for $\mathrm{CN}$ became negative (2/28), $\mathrm{CN}$ antigen titer decreased from 1:64 (3/3) to 1:16 (4/14) (Table 3), and the left pleural effusion and parenchymal shadow were resolved by the end of May. Since the serum $\mathrm{CN}$ antigen remained positive, flucytosine (5-FC) and fluconazole (FCZ) were continued orally. She was discharged from the hospital on June 18 , and has since been treated with PSL at a daily dose of $5 \mathrm{mg}, \mathrm{FCZ}$ at $100 \mathrm{mg}$ and 5-FC at $2 \mathrm{~g}$ twice weekly following hemodialysis at the outpatient clinic.

\section{Discussion}

Cryptococcus neoformans infection rarely occurs in healthy or compromised persons. As for pulmonary manifestations of $\mathrm{CN}$ infection, parenchymal nodules are common in the case of healthy persons. Conversely, diffuse interstitial infiltrates, alveolar consolidation, ground glass shadow, and mediastinal or hilar lymphadenopathy are most commonly seen in cases of compromised persons with a disease such as AIDS $(4,6-10)$. In the present case, a localized interstitial infiltrate shadow was observed on the chest CT (Fig. 2), but was not considered typical of $\mathrm{CN}$ infection, probably due to the fact that our case was not an AIDS patient.

Among the parenchymal, nodular, and pleural abnormalities, pleural abnormality is reported to be the most uncommon pulmonary manifestation of $\mathrm{CN}$ infection. The frequencies of patients with pleural effusion due to $\mathrm{CN}$ infection are reported

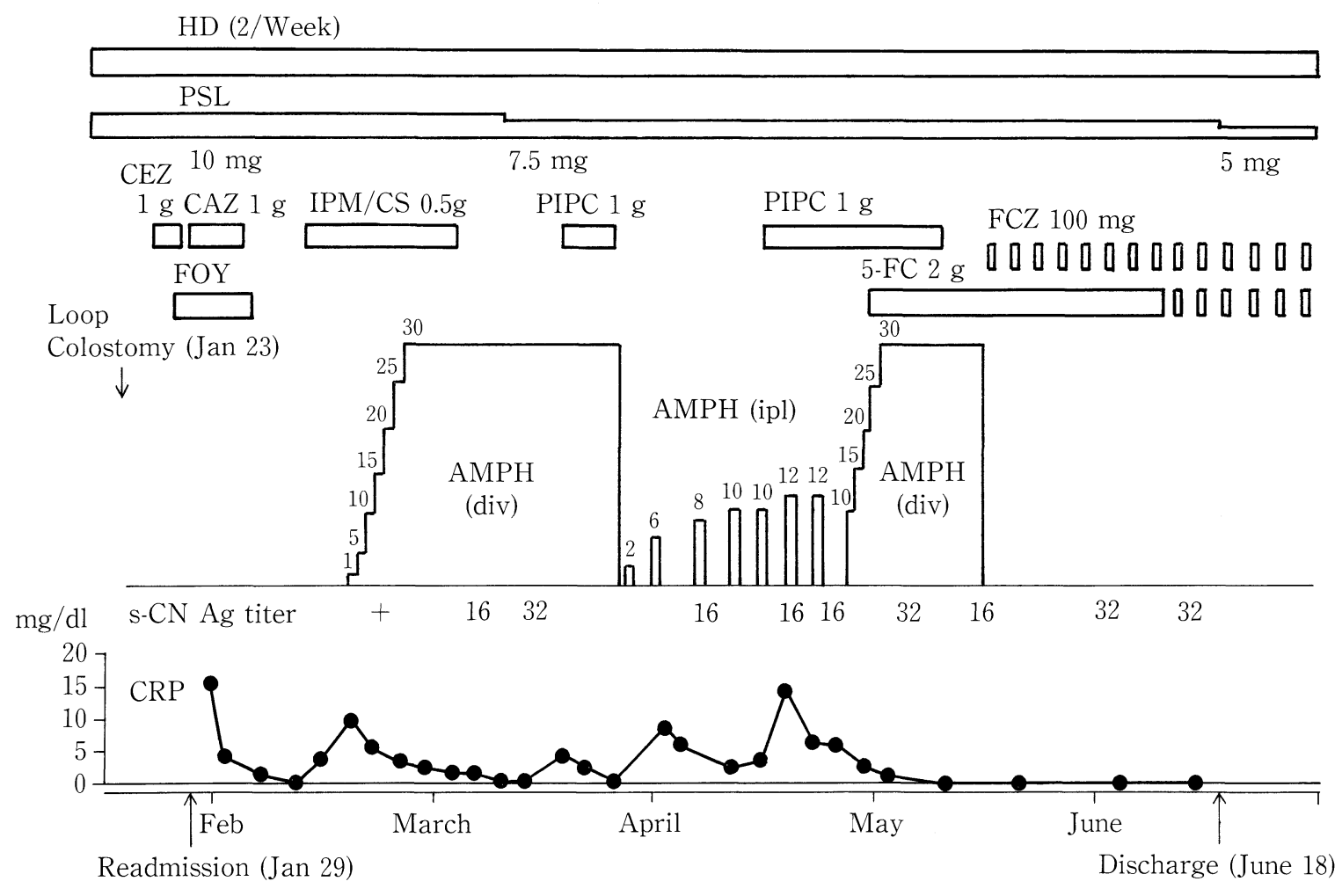

Figure 3. Clinical course. 
Pleural Effusion due to C. neoformans

Table 3. Characteristics of Pleural Effusion following Treatment with AMPH

\begin{tabular}{|c|c|c|c|c|c|c|c|c|c|}
\hline АМРН* & $2 / 18$ & $2 / 28$ & $3 / 3$ & $3 / 17$ & $3 / 25$ & $4 / 1$ & $4 / 7$ & $4 / 14$ & $4 / 17$ \\
\hline $\mathrm{TP}(\mathrm{g} / \mathrm{dl})$ & 2.5 & 2.4 & 2.5 & 2.5 & 1.9 & 2.5 & 2.6 & 2.5 & 2.8 \\
\hline $\operatorname{ALB}(\mathrm{g} / \mathrm{dl})$ & 1.4 & 1.4 & 1.4 & 1.3 & 1.1 & 1.3 & 1.4 & 1.3 & 1.3 \\
\hline $\mathrm{LDH}(\mathrm{IU} / l)$ & 364 & 147 & 141 & 134 & 133 & 274 & 283 & 273 & 486 \\
\hline $\operatorname{WBC}(/ \mu \mathrm{l})$ & 4,320 & 858 & 594 & 232 & 144 & & & & \\
\hline Culture & $(+)$ & $(-)$ & $(-)$ & $(-)$ & $(-)$ & $(-)$ & $(-)$ & $(-)$ & $(-)$ \\
\hline $\mathrm{CN}$ antigen titer & & $(+)$ & $1: 64$ & & & & & $1: 16$ & \\
\hline
\end{tabular}

*Amphotericin B (AMPH) was administered intravenously (div) from $2 / 21$ to $3 / 24$, and intrapleurally (ipl) from $3 / 25$ to $4 / 21$.

to be $0 / 10(4), 1 / 12$ (8), and 3/14 (9). In Japan, Taguchi et al (5) reported such a case with impaired cellular immunity secondary to human T-lymphocyte virus type 1 (HTLV-1) infection. In 1980, Young et al (3) reviewed 30 cases with cryptococcal pleural effusions based on the English literature. Probably, around 50 such cases have been documented to date, but this is still very few. They stated that treatment with corticosteroid and/or immunosuppressive drugs was the most common predisposing condition for such cases. The present case had also undergone treatment with PSL over a long period, and her chronic renal failure itself may also have been immunosuppressive. The characteristic of pleural effusion in our case was exudate and lymphocyte predominancy, and these findings were in agreement with the reports of several investigators (3, 6). According to the review literature (3), positive rates for cryptococci in pleural fluid are not so high; only 11 out of 26 cases were shown to be positive. Salyer and Sayler (2) reported that negative cultures might be due to the fact that the effusion results not from the growth of organisms, but rather from the release of antigen into the pleural fluid, just as occurs in $M$. tuberculosis. In fact, they had identified subpleural nodule as a part of the primary pulmonary lymph nodal complex in 6 out of 7 autopsy cases with pleural cryptococcosis. In the present case, the effusion seemed to result from the growth of the organism in the pleural cavity.

The cryptococcal antigen was positive in both the fluid and serum in our case. The cryptococcal antigen test is reported to be a useful adjunct in confirming a diagnosis and in assessing the response to treatments (3). Diamond and Bennett (12) showed that patients with cryptococcal meningitis who had relapsed had persistently high posttreatment titers of cryptococcus antigen in their serum or cerebrospinal fluid. They warned that there is a high possibility of relapse in patients who continue to receive daily corticosteroid therapy at doses of over $20 \mathrm{mg}$ of PSL after undergoing antifungal therapy. The cryptococcal antigen in the serum is still positive in our case, so we will continue to administer antifungal drugs orally for a certain period.

Although cryptococcal pleural effusion is uncommon, this disease should be considered in patients who have serious underlying diseases, especially when they have been receiving corticosteroid for a long period of time. We think it is important to include the cryptococcal antigen test or culture in the evaluation of pleural effusion in such patients.

\section{References}

1) Epstein R, Cole R, Hunt KK Jr. Pleural effusion secondary to pulmonary cryptococcosis. Chest 61: 296, 1972.

2) Salyer WR, Salyer DC. Pleural involvement in cryptococcosis. Chest 66: 139, 1974.

3) Young EJ, Hirsh DD, Fainstein V, Williams TW. Pleural effusion due to Cryptococcus neoformans: a review of the literature and report of two case with cryptococcal antigen determinations. Am Rev Respir Dis 121: 743,1980

4) Suster B, Akerman M, Orenstein M, Wax MR. Pulmonary manifestations of AIDS: review of 106 episodes. Radiology 161: 87, 1986.

5) Taguchi H, Kotani S, Sugito S, Kobayashi M, Kubonishi I, Miyoshi I. Cryptococcal pleural effusion in an HTLV-I carrier with Waldenstroem's macroglobulinemia. Acta Medica Okayama 46: 45, 1992.

6) Joseph J, Strange C, Sahn SA. Pleural effusions in hospitalized patients with AIDS. Ann Intern Med 118: 856, 1993.

7) Sider L, Gabriel H, Curry DR, Pham MS. Pattern recognition of the pulmonary manifestations of AIDS on CT scans. Radiographics 13: 771, 1993.

8) Sider L, Westcott MA. Pulmonary manifestations of cryptococcosis in patients with AIDS: CT features. J Thorac Imaging 9: 78, 1994.

9) Friedman EP, Miller RF, Severn A, Williams IG, Shaw PJ. Cryptococcal pneumonia in patients with the acquired immunodeficiency syndrome. Clin Radiol 50: 756, 1995.

10) Meyohas MC, Roux P, Bollens D, et al. Pulmonary cryptococcosis: localized and disseminated infections in 27 patients with AIDS. Clin Infect Dis 21: 628, 1995.

11) Steinbrocker $\mathrm{O}$, Traeger $\mathrm{CH}$, Batterman RC. Therapeutic criteria in rheumatoid arthritis. JAMA 140: 659, 1949.

12) Diamond RD, Bennett JE. Prognostic factors in cryptococcal meningitis: a study in 111 cases. Ann Intern Med 80: 176, 1974. 